\title{
Descriptors for High-Performance Nitrogen-Doped Carbon Catalysts in Acetylene Hydrochlorination
}

\author{
Ronghe Lin, Selina K Kaiser, Roland Hauert, and Javier Perez-Ramirez \\ ACS Catal., Just Accepted Manuscript •DOI: 10.1021/acscatal.7b03031 • Publication Date (Web): 11 Dec 2017 \\ Downloaded from http://pubs.acs.org on December 18, 2017
}

\section{Just Accepted}

"Just Accepted" manuscripts have been peer-reviewed and accepted for publication. They are posted online prior to technical editing, formatting for publication and author proofing. The American Chemical Society provides "Just Accepted" as a free service to the research community to expedite the dissemination of scientific material as soon as possible after acceptance. "Just Accepted" manuscripts appear in full in PDF format accompanied by an HTML abstract. "Just Accepted" manuscripts have been fully peer reviewed, but should not be considered the official version of record. They are accessible to all readers and citable by the Digital Object Identifier (DOI $®)$. "Just Accepted" is an optional service offered to authors. Therefore, the "Just Accepted" Web site may not include all articles that will be published in the journal. After a manuscript is technically edited and formatted, it will be removed from the "Just Accepted" Web site and published as an ASAP article. Note that technical editing may introduce minor changes to the manuscript text and/or graphics which could affect content, and all legal disclaimers and ethical guidelines that apply to the journal pertain. ACS cannot be held responsible for errors or consequences arising from the use of information contained in these "Just Accepted" manuscripts. 


\title{
Descriptors for High-Performance Nitrogen-Doped Carbon Catalysts in Acetylene Hydrochlorination
}

\author{
Ronghe Lin, ${ }^{+, \S}$ Selina K. Kaiser, ${ }^{\dagger, \S}$ Roland Hauert, ${ }^{\ddagger}$ and Javier Pérez-Ramírez ${ }^{*, \dagger}$ \\ ${ }^{\dagger}$ Institute for Chemical and Bioengineering, Department of Chemistry and Applied Biosciences, ETH Zurich, Vladi- \\ mir-Prelog-Weg 1, 8093 Zurich, Switzerland \\ ${ }^{\ddagger}$ Swiss Federal Laboratories for Materials Science and Technology, EMPA, Überlandstrasse 129, 860o Dübendorf, \\ Switzerland
}

\begin{abstract}
Nitrogen-doped carbons are promising materials for a broad range of applications. However, their rational design is greatly hampered by the lack of efficient methods to control the nitrogen speciation, which not only causes controversy about the roles of specific nitrogen functionalities, but also hinders investigations into other physicochemical characteristics of these materials. We herein present a cutting-edge strategy that allows a systematic tuning of the electrical conductivity of polyaniline-derived N-doped carbons at a defined nitrogen speciation and content, and similar porous properties. By applying these model systems in acetylene hydrochlorination, a major industrial technology for the production of polyvinylchloride, we provide insights into the active sites and the reaction mechanism and disclose two key catalytic descriptors for $\mathrm{N}$-doped carbons in this reaction: (i) a high content of pyrrolic-N functionalities, promoting the adsorption of the reactants, and (ii) good electrical conductivity, likely influencing the surface diffusion of adsorbed species. Since increasing the electrical conductivity leads to a reduced nitrogen content, the interplay between these two properties must be carefully controlled to maximize catalytic performance. This understanding enabled the design of the first $\mathrm{N}$ doped carbon catalyst that rivals the unprecedented activity of benchmark gold-based systems in acetylene hydrochlorination.
\end{abstract}

KEYWORDS: acetylene hydrochlorination, $N$-doped carbon, descriptor, nitrogen functionality, electrical conductivity

\section{INTRODUCTION}

Carbon nanomaterials, such as graphene and carbon nanotubes have gained continuous interest in diverse fields such as energy storage, ${ }^{1} \mathrm{CO}_{2}$ capture ${ }^{2,3}$ and catalysis. $^{4-9}$ The versatility originates from the rich physicochemical characteristics that can be adjusted by different methods including, thermal ${ }^{10}$ and chemical activation, ${ }^{11,12}$ surface modification, ${ }^{13}$ and heteroatom doping. ${ }^{5,1,15}$ Particularly, the introduction of $p$-block elements such as $\mathrm{N}$, $\mathrm{B}, \mathrm{P}, \mathrm{S}$, or Si offers a valuable approach to tailor the electronic properties, as it induces a redistribution of $p$ electrons, which creates electron-donating or electronaccepting sites and thus influences the adsorption properties of the carbon materials. ${ }^{16}$ For many applications, nitrogen evolved as the dopant of choice, which can be attributed to the similar electronegativity and electron affinity to carbon. ${ }^{16}$ Typically, N-doped carbons contain diverse nitrogen functionalities, including graphitic-, pyridinic-, pyrrolic-, and oxidized nitrogen that contribute differently to the overall material properties. ${ }^{17}$ The simultaneous presence of these different nitrogen functionalities causes difficulties in establishing their structure-performance relationship. Strategies to systematically tune individual physicochemical characteristics of $\mathrm{N}$ doped carbons, including their nitrogen speciation, po- rous properties, and electrical conductivity are essential to enable their rational design for targeted applications.

Metal-free carbon materials are desirable catalysts for the production of vinyl chloride monomer (VCM) via acetylene hydrochlorination, a major industrial technology based on abundant and low-cost coal reserves that is mainly applied in China. ${ }^{18,19}$ The process relies on a mercuric chloride catalyst supported on activated carbon (1015 wt. $\left.\% \mathrm{HgCl}_{2} / \mathrm{AC}\right){ }^{6,8}$ The volatility of the highly toxic $\mathrm{HgCl}_{2}$ phase under typical operation conditions causes annual mercury emissions $>40$ ton, which led to the prohibition of mercury usage in polyvinylchloride (PVC) production from 2020 at the Minamata Convention on Mercury. ${ }^{20}$ This has sparked the search for environmentally benign catalysts, of which carbon-supported goldbased systems stand out as the most promising candidates, surpassing the performance of the mercury-based catalysts. ${ }^{21-25}$ In spite of their remarkable activity, the high cost and insufficient lifetime of gold-based catalysts prevent their wide implementation. ${ }^{26,27}$ In this respect, exploration of earth-abundant materials based on metal-free carbons is highly desirable for the sustainable expansion of the technology. However, to date $\mathrm{N}$-doped carbon materials are still not competitive with gold catalysts due 
a
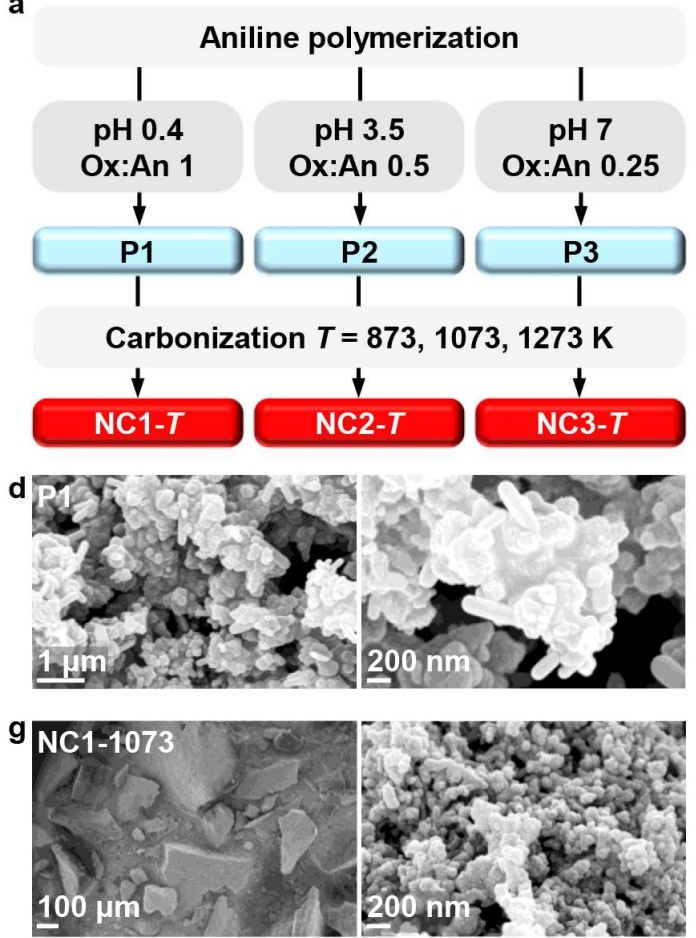
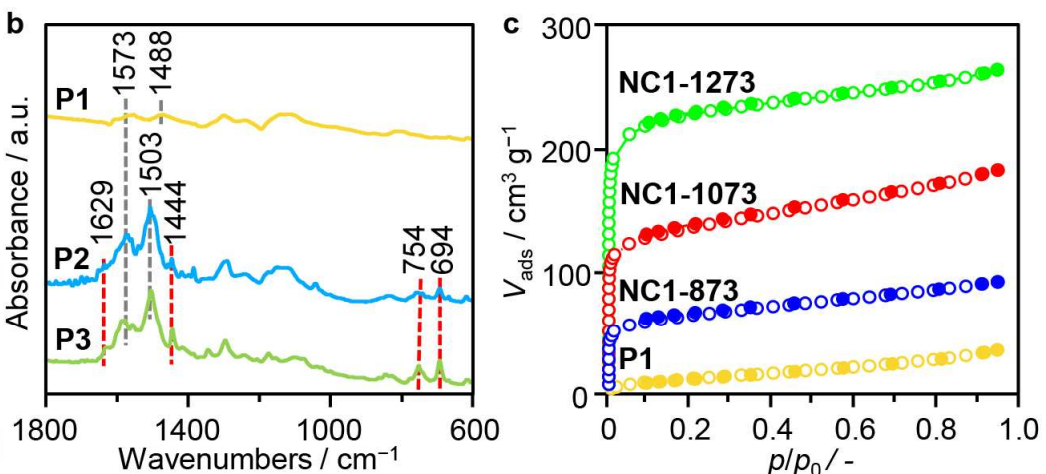
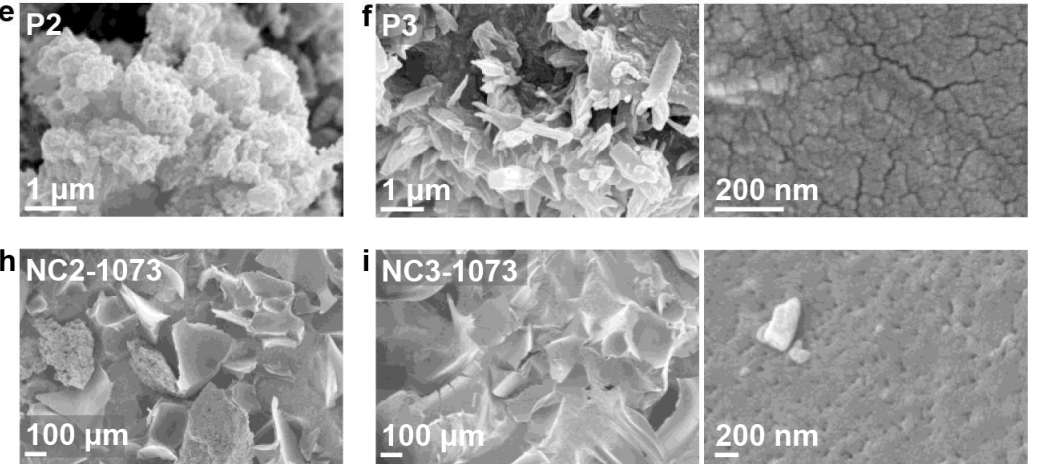

Figure 1. Synthesis and characterization of polyaniline precursors and the derived N-doped carbons. a, Strategy for the controlled synthesis of $\mathrm{N}$-doped carbons $(\mathrm{NC})$, comprising the oxidative polymerization of aniline (An) to polyaniline $(\mathrm{P})$ at different $\mathrm{pH}$, using varying amounts of ammonium persulfate as the oxidant (Ox), followed by carbonization at distinct temperatures $(T)$. b, FTIR spectra of $\mathrm{P}_{1}-\mathrm{P}_{3}$, showing their distinct degree of polymerization, as indicated by the presence of aniline oligomers in $\mathrm{P}_{2}$ and $\mathrm{P}_{3}$ (shifts highlighted by red vertical lines) c, Ar isotherms of $\mathrm{P}_{1}$ and $\mathrm{NC}_{1}-T$. $\mathbf{d}-\mathbf{i}$, SEM images of the polyaniline precursors (d-f) and their corresponding $\mathrm{N}$-doped carbons $(\mathbf{g}-\mathbf{i})$.

to their low space-time yield and poor stability under industrially relevant conditions $(T=403-453 \mathrm{~K}, P=1.5$ bar, $\left.\mathrm{HCl}: \mathrm{C}_{2} \mathrm{H}_{2}=1.1: 1\right) .^{6-8}$ In order to guide rational catalyst design, it is crucial to gain a deeper understanding on the nature of the active site, catalytic descriptors, and the underlying reaction mechanism. Particularly, the role of the nitrogen content and speciation causes controversy. ${ }^{6,8,28-31}$ For polymer-derived $\mathrm{N}$-doped carbons it is frequently observed that an increment in the calcination temperature, generally accompanied by a gradual decrease in the nitrogen content, initially leads to a steady increase in activity, until temperatures of $\approx 1200 \mathrm{~K}$ are reached and the performance drastically drops, likely due to the high $\mathrm{N}$ loss in the material. ${ }^{29,32}$ Previous explanations for the initial activity increase were based on an increment in the surface area and/or the removal of oxygen containing groups. ${ }^{8,32}$ However, both parameters could not be properly assessed since the nitrogen speciation and content are strongly temperature dependent, hampering the possibility of generating model catalysts to understand the roles of these parameters. Another plausible physical property that correlates with the calcination temperature and may influence the catalytic performance by improving the access to the active sites, is the electrical conductivity $(\sigma)$. Interestingly, the interplay between $\sigma$ and the nitrogen content and speciation in $\mathrm{N}$-doped carbons can indeed explain the observed volcano behavior between catalytic activity and calcination temperature, as has been described in the the oxygen reduction reaction (ORR). ${ }^{33,34}$ These observations inspired us to investigate a possible interplay of these descriptors for $\mathrm{N}$-doped carbons in acetylene hydrochlorination. The great challenge here lies in the development of a synthesis strategy that allows to systematically tune the electrical conductivity without changing other material properties that could be catalytic descriptors themselves.

Herein, we introduce an innovative strategy for the synthesis of polyaniline-derived $\mathrm{N}$-doped carbons with finely tunable electrical conductivity at defined content and distribution of nitrogen functionalities (pyridinic-, pyrrolic-, graphitic- and oxidized-N), and porous properties, including the total surface area $\left(S_{\mathrm{BET}}\right)$, micropore surface area $\left(S_{\text {micro }}\right)$ and micropore volume $\left(V_{\text {micro }}\right)$. With this library of model catalysts on hand, we conducted the first systematic study on the correlation between electrical conductivity and catalytic activity and at the same time reassessed previously proposed potential descriptors in acetylene hydrochlorination (N-functionalities, $S_{\mathrm{BET}}$, oxygen content). We identified an interplay between catalytic descriptors, deepened the understanding of the active sites and shed light on the reaction mechanism. Finally, these new insights enabled the development of a novel Ndoped carbon catalyst that combats with benchmark gold 
Table 1. Characterization data of the polyaniline precursors and their carbonized products, reference nitrogen-containing carbon materials, and benchmark gold-based catalysts.

\begin{tabular}{|c|c|c|c|c|c|c|c|c|c|}
\hline Sample & $\begin{array}{c}\mathrm{N}^{a} \\
\text { (wt.\%) }\end{array}$ & $\begin{array}{c}\mathrm{N}: \mathrm{C}^{a} \\
(\mathrm{~mol}: \mathrm{mol})\end{array}$ & $\begin{array}{c}V_{\text {total }}^{b} \\
\left(\mathrm{~cm}^{3} \mathrm{~g}^{-1}\right)\end{array}$ & $\begin{array}{c}V_{\text {micro }}{ }^{c} \\
\left(\mathrm{~cm}^{3} \mathrm{~g}^{-1}\right)\end{array}$ & $\begin{array}{c}S_{\text {micro }}{ }^{c} \\
\left(\mathrm{~m}^{2} \mathrm{~g}^{-1}\right)\end{array}$ & $\begin{array}{c}S_{\mathrm{BET}}{ }^{d} \\
\left(\mathrm{~m}^{2} \mathrm{~g}^{-1}\right)\end{array}$ & $\begin{array}{c}\sigma^{e} \\
\left(\mathbf{S ~ m}^{-1}\right)\end{array}$ & $\begin{array}{c}c_{\mathrm{C}_{2} \mathrm{H}_{2}}^{f} \\
\left.(\mu \mathrm{mol} \mathrm{g})^{-1}\right)\end{array}$ & $\begin{array}{c}\mathrm{C}_{\mathrm{CO}_{2}}^{g} \\
\left(\mu \mathrm{mol} \mathrm{g} \mathrm{g}^{-1}\right)\end{array}$ \\
\hline $\mathrm{P}_{1}$ & 11.1 & 0.18 & 0.10 & 0.00 & o & 28 & conducting & - & - \\
\hline $\mathrm{P}_{2}$ & 12.5 & 0.17 & 0.08 & 0.00 & o & 18 & insulating & - & - \\
\hline $\mathrm{P}_{3}$ & 12.8 & 0.15 & 0.00 & 0.00 & o & 3 & insulating & - & - \\
\hline $\mathrm{NC}_{1}-873$ & 13.7 & 0.17 & 0.11 & 0.05 & 128 & 193 & $8 \times 10^{-7}$ & 337 & 33 \\
\hline $\mathrm{NC} 1-1073$ & 9.8 & 0.13 & 0.21 & 0.10 & 245 & 313 & 1.4 & 267 & 34 \\
\hline $\mathrm{NC}_{1-1273}$ & $4 \cdot 5$ & 0.05 & 0.31 & 0.23 & 605 & 686 & 8.2 & 114 & 9 \\
\hline $\mathrm{NC}_{2}-873$ & 12.6 & 0.14 & 0.08 & 0.03 & 95 & 148 & $2 \times 10^{-7}$ & 257 & 22 \\
\hline $\mathrm{NC}_{2}-1073$ & 8.9 & 0.11 & 0.15 & 0.12 & 309 & 343 & 0.02 & 190 & 20 \\
\hline $\mathrm{NC}_{2}-1273$ & 4.2 & 0.04 & 0.23 & 0.16 & 430 & 515 & 0.3 & 68 & 5 \\
\hline $\mathrm{NC}_{3}-873$ & 12.8 & 0.15 & 0.06 & 0.03 & 80 & 122 & $1 \times 10^{-7}$ & 260 & 21 \\
\hline $\mathrm{NC}_{3}-1073$ & 10.3 & 0.13 & 0.10 & 0.09 & 242 & 264 & 0.02 & 208 & 30 \\
\hline $\mathrm{NC}_{3}-1273$ & 4.1 & 0.04 & 0.16 & 0.11 & 271 & 359 & 0.4 & 60 & 6 \\
\hline g- $\mathrm{C}_{3} \mathrm{~N}_{4}$ & 58.4 & 1.60 & 0.14 & 0.00 & o & 33 & insulating & 437 & 33 \\
\hline N-AC & $7 \cdot 3$ & 0.09 & 0.46 & 0.10 & 220 & 428 & 1.9 & 164 & 33 \\
\hline $\mathrm{Au} / \mathrm{AC}$ & - & - & 0.57 & 0.16 & 372 & 596 & - & - & - \\
\hline $\mathrm{Na}_{3} \mathrm{Au}\left(\mathrm{S}_{2} \mathrm{O}_{3}\right)_{2} / \mathrm{AC}$ & - & - & 0.56 & 0.11 & 240 & 490 & - & - & - \\
\hline
\end{tabular}

${ }^{a}$ Elemental analysis. ${ }^{b}$ Volume at $p / p_{0}=0.98 .{ }^{c} t$-plot method. ${ }^{d}$ BET method. ${ }^{e}$ Electrical conductivity. ${ }^{f} \mathrm{C}_{2} \mathrm{H}_{2}-\mathrm{TPD} .{ }^{g} \mathrm{CO}_{2}-\mathrm{TPD}$.

systems, closing the gap between carbon- and noble metal -based catalyst families in acetylene hydrochlorination.

\section{RESULTS AND DISCUSSION}

Synthesis and characterization of polyaniline precursors and their nitrogen-doped carbon products. We herein present a unique two-step strategy that enables the synthesis of $\mathrm{N}$-doped carbons with comparable nitrogen content and functionalities, oxygen content and porous properties, but varying electrical conductivity. Our approach is based on (i) the modification of decisive synthesis parameters in the oxidative polymerization of aniline, yielding a spectrum of polyanilines with different molecular weight, morphology and electrical conductivity and (ii) a subsequent carbonization step that allows to finely tune the targeted nitrogen speciation of the final $\mathrm{N}$-doped carbons (Figure 1a).

Polyanilines with a broad range of molecular weight $\left(M_{\mathrm{w}}=5,000-19,000 \mathrm{~g} \mathrm{~mol}^{-1}\right)$ were prepared by adjusting the molar oxidant-to-aniline (Ox:An) ratio and the initial $\mathrm{pH}$ of the solution (Figure S2, see for details the Supporting Information). ${ }^{35,36}$ For detailed analysis, three samples $\left(\mathrm{P}_{1}, \mathrm{P}_{2}\right.$, and $\left.\mathrm{P}_{3}\right)$ were selected as representatives of this polyaniline library, as they cover the whole range of $\mathrm{pH}$ and Ox:An ratios investigated (Figures 1a and $\mathrm{S}_{2}$ ). The molecular weight $\left(M_{\mathrm{w}}\right)$ of the selected polymers decreases in the order of $\mathrm{P}_{1}>\mathrm{P}_{2}>\mathrm{P}_{3}$, indicating the distinct degree of polymerization. This result is corroborated by Fourier transform infrared spectroscopic (FTIR) analysis. Aniline oligomers, with typical infrared absorptions at 1444, 754, and $694 \mathrm{~cm}^{-1}$ (Figure $\mathrm{lb}$ ), ${ }^{37,38}$ were present in $\mathrm{P}_{2}$ and $\mathrm{P}_{3}$, but absent in P1. In line with this observation, P1 was found to be conducting while the other two samples are insulating (Table 1), likely due to the shorter conjugation length in the carbon backbone. ${ }^{35,36}$ Scanning electron microscopy (SEM) shows distinct morphologies of these samples (Figures 1d-e). For $\mathrm{P}_{3}$, a petal-like structure intersected by many nanoflakes with a thickness of $c a .50 \mathrm{~nm}$ and a length of several microns is observed, which likely originates from the stacking of aniline oligomers. With an increasing degree of polymerization, a coral reef-like structure assembled by several nanogranules (50-100 $\mathrm{nm}$ ) is observed for $\mathrm{P}_{2}$, whereas a mixture of larger granules ( $>200 \mathrm{~nm}$ ) and nanorods dominates in P1.

The polyaniline precursors were calcined in nitrogen atmosphere to generate a comprehensive range of $\mathrm{N}$ doped carbons. Since the carbonization temperature not only contributes significantly to the development of important physical characteristics of the carbon host, including the electrical conductivity and the porous properties (surface area and pore volume), but also determines the nitrogen speciation (total $\mathrm{N}$ content and distribution of nitrogen functionalities), we first investigated this parameter by temperature-programmed desorption (TPD) analysis. The results show that the critical temperature range in which $\mathrm{HCN}$ evolution occurs is around 700-1000 K (Figure $\mathrm{S}_{4}$ ). On the basis of X-ray diffraction analysis, we confirmed the successful incorporation of nitrogen atoms into the carbon matrix for the samples calcined at $\geq 873 \mathrm{~K}$, as is indicated by a $2.2^{\circ}$ shift of the (oo2) plane to the low $2 \theta$ angle in respect to graphite 
(Figure $\mathrm{S}_{5}$ ). Hence, carbonization temperatures of 873$1273 \mathrm{~K}$ were selected to generate the spectrum of N-doped carbon materials. The significantly enhanced surface area

$\left(S_{\mathrm{BET}}\right)$ of the carbon materials compared to the polyaniline precursors $\left(S_{\mathrm{BET}}<30 \mathrm{~m}^{2} \mathrm{~g}^{-1}\right.$, Table 1$)$ and the generation of micropores through the annealing treatment were evidenced by argon sorption (Figure ic and Figure S6).

The influence of the carbonization temperature on the total nitrogen content was studied by elemental analysis. As expected, the nitrogen contents are all in a narrow range of $11-13 \mathrm{wt} . \%$ for the different polyanilines, and they gradually decrease upon increasing calcination temperature (Table 1). The sulfur and chloride impurities in the precursors, as detected by FTIR and elemental analysis, were largely removed by the calcination process. This is also verified by the X-ray photoelectron spectroscopic (XPS) analysis (Figure $\mathrm{S} 7$ ), which corroborates the metalfree nature of the carbon materials. SEM examination of $\mathrm{N}$-doped carbons derived from the key polyanilines reveals a clear morphology transition from (i) smooth nanosheets, with a size of several hundreds of microns in $\mathrm{NC}_{3-1073}$, to (ii) a mixture of smooth nanosheets and rough nanoplates in $\mathrm{NC}_{2}-1073$, and to (iii) rough nanoplates, comprising small nanogranules in $\mathrm{NC}_{1-1073}$ (Figures $1 \mathrm{~g}-\mathrm{i}$ ). The distinct morphologies of these materials are well reflected by their different electrical conductivity $(\sigma)$, which is highly dependent on the precursor and the calcination temperature (Table 1 ). Firstly, there is a positive correlation between the molecular weight of polyanilines and their electrical conductivity, which can be partly preserved throughout the annealing treatment. However, the key parameter is the carbonization temperature which decides whether the $\mathrm{N}$-doped carbons are insulating $(T=873 \mathrm{~K})$ or conducting $(T \geq 1073 \mathrm{~K})$.

Evolution of nitrogen functionalities from polyanilines to nitrogen-doped carbons. Distinct nitrogen functionalities of high- and low- $M_{\mathrm{w}}$ polyanilines $\mathrm{P}_{1}$ and $\mathrm{P}_{3}$ and their carbonized products were characterized by ${ }^{15} \mathrm{~N}$ solid-state cross-polarization magic angle spinning nuclear magnetic resonance (CP/MAS NMR) spectroscopy and XPS. In accordance with expectations, the NMR spectra of the ${ }^{15} \mathrm{~N}$ enriched polyanilines differ significantly (Figure S8). In the case of $\mathrm{P}_{3}$, a larger fraction of amine-type nitrogens (chemical shift $\delta \approx 50 \mathrm{ppm}$ ) in comparison to imine functionalities $(\delta \approx 300 \mathrm{ppm})$ is observed, which likely originates from the under-stoichiometric amounts of the oxidant applied. ${ }^{39}$ Additional resonances at $\delta=85$, 95, and $101 \mathrm{ppm}$ can be assigned to the $s p^{3}$ hybridized nitrogens in phenazine-like structures, ${ }^{40}$ which agrees well with the $1629 \mathrm{~cm}^{-1}$ band in the FTIR spectrum (Figure $1 b$ ). In the case of $\mathrm{P} 1$, much broader resonances are observed, which is likely a consequence of the high electrical conductivity of this polymer. The broad peak in the range of 75-140 ppm can be tentatively assigned to the oxidized amine and protonated imine groups. ${ }^{39}$ Accordingly, no resonances of neutral imine functionalities are observed. These results are corroborated by the $\mathrm{N}$ is XPS spectra of $\mathrm{P}_{3}$ and $\mathrm{P}_{1}$ (Figure 2a). The spectrum of $\mathrm{P}_{3}$ sug-

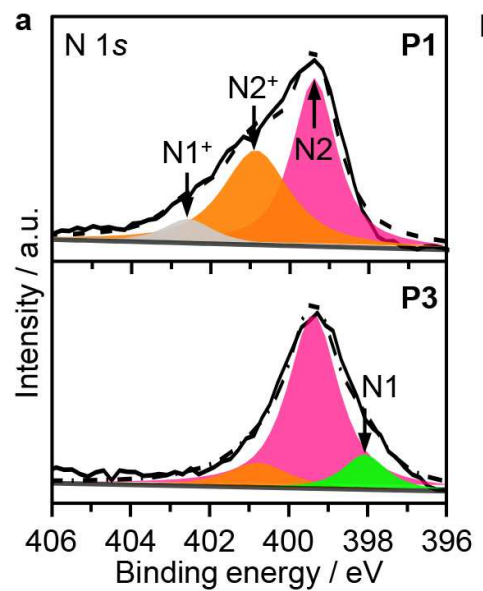

b

Quinoid imine (N1)
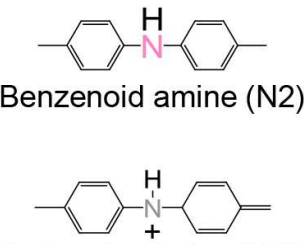

Protonated imine $\left(\mathrm{N}^{+}{ }^{+}\right)$

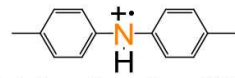

Oxidized amine $\left(\mathrm{N} 2^{+}\right)$
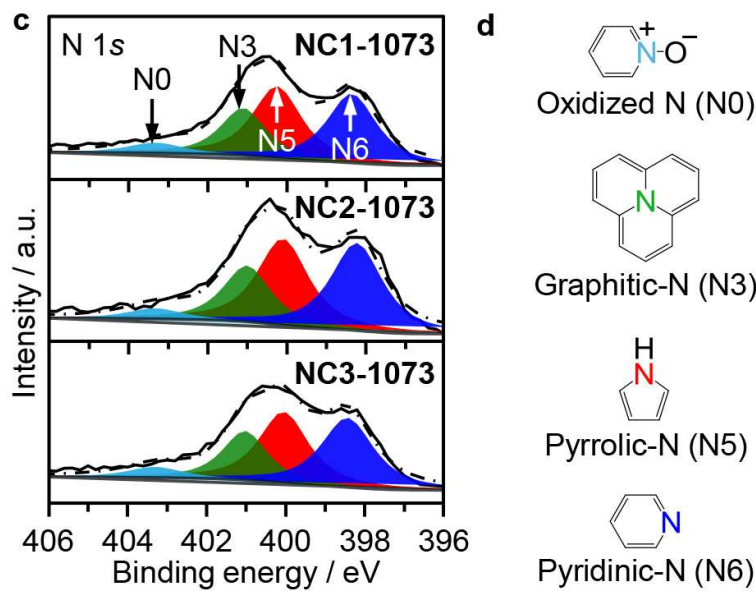

Figure 2. $\mathrm{N}$ is XPS spectra of polyaniline precursors (a) and corresponding N-doped carbons calcined at $1073 \mathrm{~K}$ (c), accompanied by the structures of all nitrogen species observed $(\mathbf{b}, \mathbf{d})$.

gests the presence of both neutral imine $\left(\mathrm{N}_{1}\right.$, $\mathrm{BE}=398.1 \pm 0.1 \mathrm{eV})$ and amine $\left(\mathrm{N}_{2}, \mathrm{BE}=399.3 \pm 0.1 \mathrm{eV}\right)$ functionalities, as well as a small amount of oxidized amine groups $\left(\mathrm{N2}^{+}, \mathrm{BE}=400.8 \pm 0.1 \mathrm{eV}\right) .^{41,42}$ Besides the neutral amine functionalities, $\mathrm{P}_{1}$ contains protonated imine groups $\left(\mathrm{Ni}^{+}, \mathrm{BE}=402.6 \pm 0.1 \mathrm{eV}\right)$ and an increased fraction of oxidized amines, which likely originates from the low $\mathrm{pH}$ and the high Ox:An ratio, applied in the synthesis.

The influence of the calcination temperature on the nitrogen content and speciation in $\mathrm{N}$-doped carbons was studied by XPS (Figure S9). We observed a decrease of the total nitrogen content with increasing carbonization temperature, which agrees well with the elemental analysis (Table 1). Irrespective of the calcination temperature, all four possible nitrogen functionalities were generated: pyridinic (N6, $\mathrm{BE}=398.4 \pm 0.2 \mathrm{eV}), \quad$ pyrrolic ( $\mathrm{N}_{5}$, $\mathrm{BE}=400.4 \pm 0.2 \mathrm{eV})$, graphitic $\left(\mathrm{N}_{3}, \mathrm{BE}=401.2 \pm 0.1 \mathrm{eV}\right)$, and oxidized nitrogen $($ No, $\mathrm{BE}=403.1 \pm 0.2 \mathrm{eV}) .^{30,43,44}$ However, their percentage distribution is strongly temperaturedependent. While pyrrolic-N predominates at $873 \mathrm{~K}$ calcination at $1273 \mathrm{~K}$ favors the formation of graphitic- and oxidized nitrogens. Pyridinic- $\mathrm{N}$ is relatively stable in the investigated temperature window, which is in line with 
earlier reports. ${ }^{8,43}$ The different stability of these nitrogen moieties resulted in an almost equal distribution of pyrrolic-, pyridinic-, and graphitic- $\mathrm{N}$ sites at the intermediate calcination temperature of $1073 \mathrm{~K}$. Importantly, this

feature is also observed for $\mathrm{NC}_{1-1073}, \mathrm{NC}_{2}-1073$ and $\mathrm{NC}_{3}-$ 1073-(Figure 2c). ${ }^{15} \mathrm{~N} \mathrm{CP} / \mathrm{MAS}$ NMR spectra of $\mathrm{NC}_{3}-1073$ and $\mathrm{NC}_{1-1073}$ show two broad resonances in a rough 2:1 ratio (peak area) with $\delta=110-180$ and $\delta=220-320 \mathrm{ppm}$ (Figure S8), which can be tentatively assigned to (i) pyrrolic- $(\delta \approx 50-120 \mathrm{ppm})$ and graphitic-N $(\delta \approx 140 \mathrm{ppm})$, and (ii) pyridinic-N $(\delta \approx 250-320 \mathrm{ppm}){ }^{45}$ corroborating the XPS results.

On the basis of XPS, ${ }^{15} \mathrm{~N} \mathrm{CP} / \mathrm{MAS}$ NMR, elemental analysis, and electrical conductivity measurements, we evidenced that the developed synthesis strategy allows a systematic tuning of the electrical conductivity of $\mathrm{N}$ doped carbons, at a defined content and distribution of nitrogen functionalities. This unique feature arises from two key aspects that prevail throughout the calcination process: (i) the partly preservation of the electrical conductivity that originates from the polyaniline and (ii) the minor influence of the precursor on the development of the nitrogen functionalities and the total $\mathrm{N}$ content in the carbonized products (Figure 2). Since the latter parameters are controllable by the calcination temperature, different sets of catalyst series can be generated. The thereby attained spectrum of model catalysts allows for the first time to thoroughly assess the electrical conductivity as a potential catalytic descriptor for $\mathrm{N}$-doped carbons in acetylene hydrochlorination without the interference of the nitrogen dopant.

Catalytic performance of nitrogen-doped carbons. Acetylene hydrochlorination over $\mathrm{N}$-doped carbon catalysts, derived from a comprehensive range of 9 systematically altered polyaniline precursors (Figure $\mathrm{S}_{2}$ ), was studied at $453-613 \mathrm{~K}$ with a $\operatorname{GHSV}\left(\mathrm{C}_{2} \mathrm{H}_{2}\right)$ of $320 \mathrm{~h}^{-1}$ (gas hourly space velocity based on acetylene, Figure S1o). First, the effect of the polyaniline precursor on the hydrochlorination activity was studied. Albeit in all cases the selectivity to VCM was virtually $100 \%$, the activity varied considerably. Interestingly, an S-shape correlation between the catalytic activity and the molecular weight of the polyaniline precursors was obtained (Figure Si1). At first, the VCM yield, $Y(\mathrm{VCM})$, increased with increasing $M_{\mathrm{w}}$, until a plateau was reached at $M_{\mathrm{w}} \approx 13,000 \mathrm{~g} \mathrm{~mol}^{-1}$. Accordingly, the $Y(\mathrm{VCM})$ achieved with $\mathrm{NC}_{1-1073}$ is almost three times higher than that of $\mathrm{NC}_{3}-1073$ ( $\left.81 \% v s .33 \%\right)$. As already pointed out before, there is a positive correlation between the molecular weight of polyanilines and their electrical conductivity. Since the latter is partly preserved in the Ndoped carbons, it can be anticipated that the observed activity indeed correlates to the electrical conductivity. The carbonization temperature, being the crucial parameter that determines the $\mathrm{N}$ speciation, and content and also coins the electrical conductivity, exerted a significant effect on the activity, as was confirmed for each polyaniline precursor. In accordance with literature reports, ${ }^{2,32}$ a common volcano curve was obtained, indicating that a
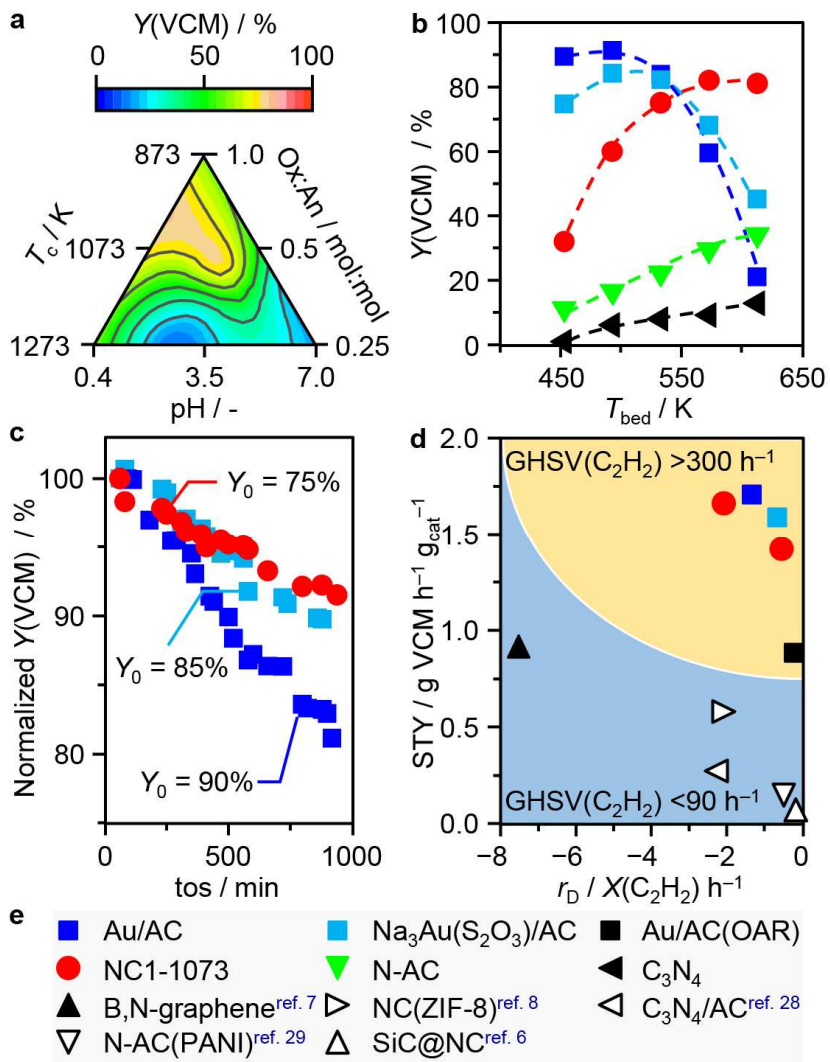

Figure 3. Catalytic performance of polyaniline-derived Ndoped carbon materials in acetylene hydrochlorination. a, Ternary contour plot of the yield of VCM, Y(VCM), at $573 \mathrm{~K}$, as a function of different process parameters, derived from 27 samples (Figure Sio). b, Yield of VCM, Y(VCM), as a function of increasing catalyst bed temperature, $T_{\text {bed }}$, over various $\mathrm{N}$-containing carbon materials and the benchmark gold-based catalysts. c, Stability performance for $\mathrm{NC}_{7-1073}$, $\mathrm{Au} / \mathrm{AC}$, and $\mathrm{Na}_{3} \mathrm{Au}\left(\mathrm{S}_{2} \mathrm{O}_{3}\right)_{2} / \mathrm{AC}$. d, Comparison of space-time yield of VCM, STY(VCM), deactivation rate, $r_{\mathrm{D}}$, and gas hourly space velocity of acetylene, $\operatorname{GHSV}\left(\mathrm{C}_{2} \mathrm{H}_{2}\right)$, between the catalysts developed in this work and other metal-free carbon catalysts and the benchmark gold-based systems. Reaction conditions for a-c: $\mathrm{HCl}: \mathrm{C}_{2} \mathrm{H}_{2}: \mathrm{Ar}=44: 40: 16, F_{\mathrm{T}}=15 \mathrm{~cm}^{3} \mathrm{~min}^{-1}$, $W_{\text {cat }}=0.5 \mathrm{~g}$, and $P=1$ bar. e, Symbols for the catalysts.

calcination temperature of $1073 \mathrm{~K}$ was optimal for each type of polyaniline (Figure S1o). A correlation between the activity of all 27 catalysts with the investigated synthesis parameters, $\mathrm{pH}, \mathrm{Ox}$ :An ratio, and calcination temperature (Figure 3a), reveals the following prerequisites for highperformance $\mathrm{N}$-doped carbons derived from polyaniline: (i) a high Ox:An molar ratio and a low $\mathrm{pH}$ for the polymerization process, favoring the formation of high $M_{\mathrm{w}}$ polyanilines with conducting properties, and (ii) a mediate calcination temperature (see for details Figure S10). The origin of these preferred conditions for the respective processes strongly points at an interplay between a specific nitrogen speciation and a certain level of electrical conductivity, which will be further discussed in the next section (vide infra).

The best $\mathrm{N}$-doped carbon catalyst developed in this work, $\mathrm{NC}_{1-1073}$, was compared in a temperature ramp 
experiment with two reference carbon materials, exhibiting similar nitrogen contents, and two gold-based catalysts (Figure $3 \mathrm{~b}$ ). All samples were evaluated at a $\operatorname{GHSV}\left(\mathrm{C}_{2} \mathrm{H}_{2}\right)$ of $320 \mathrm{~h}^{-1}$, a considerable high velocity for carbon materials, in order to allow direct comparison with the literature reported activities of the gold-based catalysts. Under these conditions, a gradual increase in activity with the bed temperature was observed for all the carbon-based catalysts. The high-temperature performance of $\mathrm{NC}_{1-1073}$ is particularly outstanding with a 2and 4 -fold higher activity compared to $\mathrm{N}$-doped activated carbon (N-AC, 7.3 wt.\% N) and graphitic carbon nitride $\left(\mathrm{g}-\mathrm{C}_{3} \mathrm{~N}_{4}\right)$ at $573 \mathrm{~K}$. On the contrary, the typical operation temperature of gold-based systems is significantly lower, reaching a maximum at $493 \mathrm{~K}$, followed by a steep decline, presumably due to the sintering of gold particles. ${ }^{26,46}$ A further comparison of the short-term stability between $\mathrm{NC}_{1-1073}$ and the gold catalysts, operated at the respective optimal working temperatures, is presented in Figure 3c. The deactivation rate of $\mathrm{NC}_{1-1073}$ is comparable to the ligand-stabilized $\mathrm{Na}_{3} \mathrm{Au}\left(\mathrm{S}_{2} \mathrm{O}_{3}\right) / \mathrm{AC}$ (0.25 wt.\% Au) catalyst, whereas the pristine $\mathrm{Au} / \mathrm{AC}$ (1 wt.\% Au) system deactivates slightly faster in the investigated time frame. It is important to stress that these conclusions are solely based on the two selected reference systems, whereas in literature often better stability is reported for gold-based systems. Noteworthy, some of these catalysts reached pilot-scale and one is marketed. $^{26,27}$ Since the hotspot effect, commonly observed in such exothermic reactions, is a major reason for the deactivation of gold- and particularly mercury-based catalysts, ${ }^{26,47}$ exploitation of high-temperature-tolerant carbon materials could be a promising direction. However, for practical applications, the long-term stability of the developed $\mathrm{N}$-doped carbons under industrial relevant conditions, needs to be improved.

A general comparison of the catalytic performance, taking into account the literature reported space-time yields (STY) of VCM and deactivation rates $\left(r_{\mathrm{D}}\right)$, of metal-free carbon materials and selected gold catalysts is presented in Figure $3 d$. Albeit the state-of-the-art carbon catalysts work at much lower GHSV $\left(50-150 \mathrm{~h}^{-1}\right)$ than the goldbased systems, they still suffer from fast deactivation..$^{6,728,30,31}$ Accordingly, there is a big gap for the STY(VCM) between carbon catalysts and gold-based systems. ${ }^{27}$ This is likely the reason for the hitherto strictly separated reports of the two material classes in acetylene hydrochlorination. The catalyst developed in this work demonstrated its robustness by operating under space velocities, commonly applied for metal-based systems, at a comparable VCM yield to the benchmark gold catalysts, which enabled for the first time a comparative study between the two different catalyst families in acetylene hydrochlorination.

Descriptors for nitrogen-doped carbon catalysts in acetylene hydrochlorination. Different nitrogen functionalities in the carbon framework have been acknowledged for creating the active site in acetylene hydrochlorination. ${ }^{6,7,30,31}$ Thus, we tentatively plotted the specific
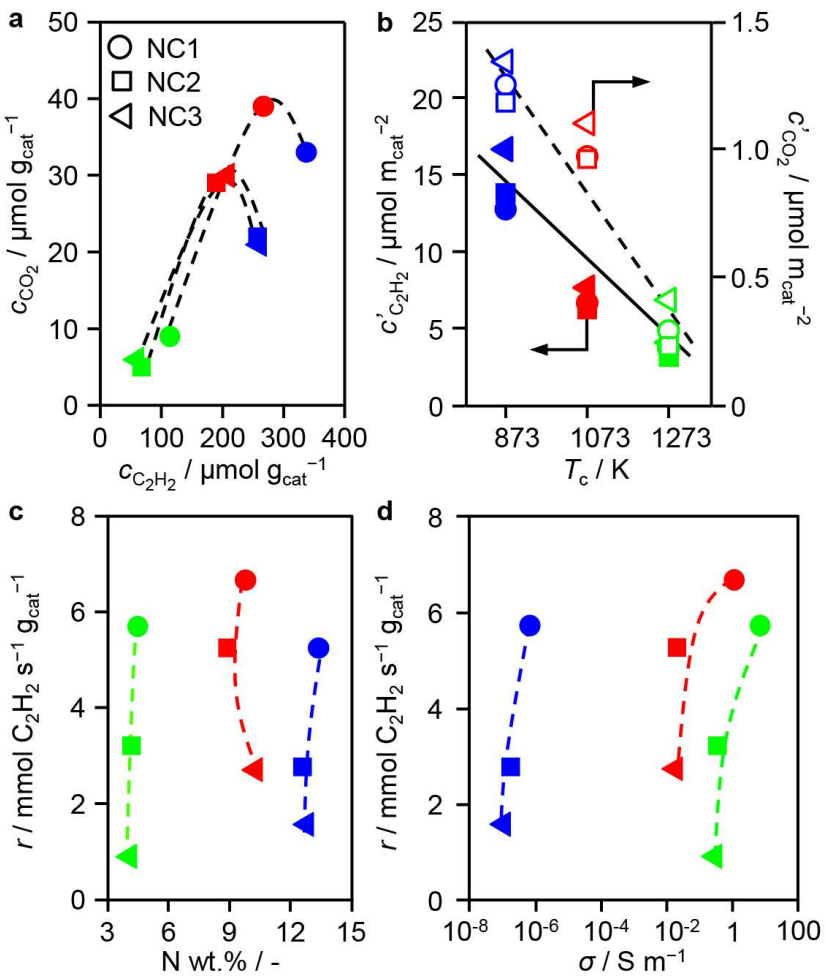

Figure 4. Descriptors for polyaniline-derived $\mathrm{N}$-doped carbons in acetylene hydrochlorination. a, $\mathrm{C}_{2} \mathrm{H}_{2}$ and $\mathrm{CO}_{2}$ adsorption capacities of NC catalysts calcined at 873 (blue), 1073 (red), and $1273 \mathrm{~K}$ (green). b, Specific adsorption capacities, normalized by total $\mathrm{N}$ content in wt.\% and total surface area $\left(S_{\mathrm{BET}}\right.$, Table $\left.^{\circ} 1\right)$, as a function of carbonization temperature. c, Reaction rate as a function of total $\mathrm{N}$ content. d, Reaction rate as a function of electrical conductivity $(\sigma)$. Note: symbols of the same color have comparable $\mathrm{N}$ content and speciation $\left(\right.$ Table $^{\circ} 1$ ).

reaction rate (normalized by $S_{\mathrm{BET}}$ ) as a function of the surface atomic content of different $\mathrm{N}$-functionalities which revealed rough linear relationships for pyrrolic-, pyridinic-, and graphitic- $\mathrm{N}$, indicating that all these functionalities could be involved in the reaction (Figure $\mathrm{S}_{12}$ ). Chemisorption properties of the three groups of NC samples were assessed with $\mathrm{C}_{2} \mathrm{H}_{2}$ - and $\mathrm{CO}_{2}$-temperatureprogrammed desorption (TPD) techniques. Due to the corrosive nature of $\mathrm{HCl}, \mathrm{CO}_{2}$ was employed as a probe molecule to examine the basicity of the materials. Interestingly, the best-performing catalysts from each group all possess relatively high adsorption capacities for both, $\mathrm{C}_{2} \mathrm{H}_{2}$ and $\mathrm{CO}_{2}$ (Figure $4 \mathrm{a}$ ), which demonstrates the importance of the $\mathrm{C}_{2} \mathrm{H}_{2}$ adsorption sites and the basicity of the $\mathrm{N}$-doped carbon materials in catalysis. This conclusion is further supported by steady-state kinetic studies. The respective partial reaction orders of $\mathrm{C}_{2} \mathrm{H}_{2}$ and $\mathrm{HCl}$ are determined to be 0.54 and 0.58 for the $\mathrm{NC}_{3}-1073$, and 0.46 and 0.74 for the $\mathrm{NC}_{1}-1073$ (Figure $\mathrm{S} 13 \mathrm{~b}$ ), which confirms the dependence of the reaction rate on the surface coverage of both reactants. To clarify whether there is competitive adsorption between the two reactants, pretreatment experiments with $\mathrm{C}_{2} \mathrm{H}_{2}$ and $\mathrm{HCl}$ were run on the $\mathrm{NC}_{1-1073}$ catalyst (Figure $\mathrm{S}_{14}$ ). The unaltered activity after these 
treatments suggests that the $\mathrm{C}_{2} \mathrm{H}_{2}$ and $\mathrm{HCl}$ molecules might be co-adsorbed at two different types of sites on this carbon catalyst.

In order to elucidate which nitrogen functionalities might be responsible for the adsorption of $\mathrm{C}_{2} \mathrm{H}_{2}$ and $\mathrm{HCl}$, respectively, we studied the variation of the adsorption capacities for both reactants with increasing calcination temperature. Since also the total nitrogen content and the surface area differ significantly between the samples calcined at different temperatures, we normalized the individual adsorption capacities for $\mathrm{C}_{2} \mathrm{H}_{2}$ and $\mathrm{CO}_{2}$ by the total nitrogen content in wt.\% and the surface area $\left(S_{\mathrm{BET}}\right)$ as given in Table ${ }^{\circ}$. The derived specific adsorption capacities $\left(c^{\prime} \mathrm{CO}_{2}\right.$ and $\left.c^{\prime}{ }^{2} \mathrm{H}_{2}\right)$ for both, $\mathrm{CO}_{2}$ and $\mathrm{C}_{2} \mathrm{H}_{2}$ decrease almost linearly with increasing carbonization temperature (Figure $4 \mathrm{~b}$ ). Since this trend is consistent with the dependence of the pyrrolic-N population on the carbonization temperature (Figure S9), it can be inferred that pyrrolic- $\mathrm{N}$ is likely the preferred adsorption site for $\mathrm{C}_{2} \mathrm{H}_{2}$ and acidic molecules. Conversely, the inverse trend is observed for graphitic- $\mathrm{N}$, demonstrating that this site is the least favored one. This observation is in line with a previous study, reporting no adsorption of $\mathrm{CO}_{2}$ on graphitic-N, but strong adsorption at pyridinic-N sites. ${ }^{5}$ Due to the unchanged concentration of pyridinic- $\mathrm{N}$ in all samples (Figure 2c), the individual effect of these sites cannot be conclusively assessed. However, as the performed steadystate kinetics hint at a two-site mechanism, we hypothesize here pyridinic- $\mathrm{N}$ as the second adsorption site, based on the high basicity of this site among the different nitrogen configurations, ${ }^{48}$ and the correspondingly favorable adsorption of $\mathrm{HCl}$ on pyridinic- $\mathrm{N}^{7}$ or its adjacent carbon atoms, ${ }^{8}$ as previously concluded on the basis of density functional theory (DFT) studies. The $\mathrm{CO}_{2}$-TPD experiments also show that $\mathrm{N}$-doped carbon materials calcined at $1073 \mathrm{~K}$ are the most basic (Figure S15), which possibly originates from the higher contribution of pyridinic-N sites (Figure S9). Taking into account the TPD and kinetic studies, we speculate that the pyrrolic- and pyridinic-N sites are likely responsible for the respective adsorption of the $\mathrm{C}_{2} \mathrm{H}_{2}$ and $\mathrm{HCl}$ molecules in acetylene hydrochlorination, which agrees well with the almost equal distribution of pyridinic- and pyrrolic N-functionalities in the best performing catalyst systems.

The comparison between $c^{\prime} \mathrm{CO}_{2}$ and $c^{\prime} \mathrm{C}_{2} \mathrm{H}_{2}$ of different $\mathrm{N}$ doped carbons, revealed comparable results for those samples calcined at the same temperature (Figure $4 \mathrm{~b}$ ), which is in line with their very similar nitrogen speciation, as demonstrated by XPS (Figure 2c). However, despite their comparable specific adsorption capacities, they show significantly differing reactivity, which proves that the nitrogen speciation as the sole descriptor for $\mathrm{N}$-doped catalysts is insufficient (Figure 4c). The oxygen content can be excluded as a potential descriptor, as the catalysts with the highest and lowest activity of the $1073 \mathrm{~K}$ series have a very similar oxygen content (Table $\mathrm{S} s$ ). Also the porous properties of $\mathrm{NC}_{1-1073}$ and $\mathrm{NC}_{3}-1073$ are quite comparable (Table 1 ), which invalidates $S_{\mathrm{BET}}$ as a catalytic descriptor. In contrast, there is a positive correlation between the hydrochlorination activity and the electrical conductivity for the catalysts from different families (Figure $4 \mathrm{~d}$ ). Since the most active catalysts of each group (red symbols in Figures 4c,d) all possess a moderate nitrogen content and high electrical conductivity, an interplay between the two factors stands to reason. On the basis of kinetic studies, we determined the activation energy $\left(E_{\mathrm{a}}\right)$ for the least and most active catalysts $\mathrm{NC}_{3}-1073$ and $\mathrm{NC}_{1-}$ 1073 (Figure S1za). The very close $E_{\mathrm{a}}$ values of 22.6 and $23.1 \mathrm{~kJ} \mathrm{~mol}^{-1}$ for the respective materials, combined with their comparable nitrogen content and speciation, indicate that both catalysts may follow the same reaction path, and that their significantly differing catalytic activity can indeed be ascribed to their distinct electrical conductivity. Considering that the $\mathrm{C}_{2} \mathrm{H}_{2}$ and $\mathrm{HCl}$ molecules are first adsorbed at different types of sites, then surface diffusion might influence the overall activity, particularly when the adsorbed species are not in close proximity or the surface coverage is low. In this case the electrical conductivity of the carbon material may influence the catalytic performance by accelerating the diffusion of charge carriers. These protons or chloride ions, which likely originate from the dissociative adsorption of the $\mathrm{HCl}$ molecule, recently gained attention in acetylene hydrochlorination on gold-based catalysts, ${ }^{25}$ whereas they are scarcely studied on the carbon-based materials. Operando studies coupled with DFT calculations are needed to reveal the precise diffusion mode, and deepen the understanding of the reaction mechanism.

In order to verify the general applicability of our two key descriptors, we studied the reference carbon materials and two samples of $\mathrm{NC}_{1-1073}$ with different degrees of deactivation ( $\alpha=40 \%$ and $90 \%$, Figure $\mathrm{S}_{16}$ ). The activity order of $\mathrm{g}_{-} \mathrm{C}_{3} \mathrm{~N}_{4}<\mathrm{N}-\mathrm{AC}<\mathrm{NC}_{1-1073}$ in acetylene hydrochlorination can indeed be explained by an interplay between (i) the increasing electrical conductivity and (ii) the higher adsorption capacities for the reactants (Table 1). The electrical conductivity of the deactivated samples decreased only slightly (Table $\mathrm{S}_{1}$ ), and the distribution of nitrogen functionalities as well as the total nitrogen content, as assessed by XPS, remained relatively stable during the catalytic run (Figure $\mathrm{S}_{17}$ and Table $\mathrm{S}_{1}$ ). However, the adsorption capacities for both $\mathrm{C}_{2} \mathrm{H}_{2}$ and $\mathrm{CO}_{2}$ were found to decrease significantly with the dropping catalytic activity (Figure $\mathrm{S} 18$ and Table $\mathrm{S} 1$ ). The formation of coke deposits (ca. 5\%), as evident from XPS and TGA (Table $S_{1}$ and Figure $S_{19}$ ) is likely connected with the major changes in the porous properties $\left(S_{\mathrm{BET}}, S_{\text {micro }}, V_{\mathrm{mi}-}\right.$ cro). Interestingly, these alterations occurred during the first $20 \mathrm{~h}$ on stream. Since at this stage the activity was still quite high $(Y(\mathrm{VCM}) \approx 60 \%)$, the influence of $S_{\mathrm{BET}}$ appears to be minor. In fact, N-AC shows comparable initial catalytic activity to $\mathrm{NC}^{-1073-20} \mathrm{~h}$, which is well in line with their similar electrical conductivity and the $\mathrm{C}_{2} \mathrm{H}_{2}$ adsorption capacity (Tables 1 and $\mathrm{S}_{1}$, and Figure S16). After $20 \mathrm{~h}$ on stream no more significant changes were observed for $\mathrm{NC}_{1-1073}$, although the activity steadily decreased during the next $50 \mathrm{~h}$. This finding may be explained by a gradual blocking of the active sites by coke 
deposits originated from VCM oligomers, ${ }^{8}$ as indicated by the slightly decreasing $\mathrm{N} / \mathrm{C}$ ratio and the steadily increasing chlorine content (Table S1).

\section{CONCLUSIONS}

In summary, we developed a cutting-edge strategy for the synthesis of $\mathrm{N}$-doped carbons with finely tunable electrical conductivity at a defined nitrogen speciation and content, and comparable porous properties. The application of these model systems in acetylene hydrochlorination gave new insights into the active sites and the reaction mechanism and disclosed catalytic descriptors fitting both, new and reference materials: (i) a high content of pyrrolic- $\mathrm{N}$ functionalities, being responsible for the adsorption of the reactants and (ii) good electrical conductivity, likely influencing the surface diffusion of adsorbed species. The adverse correlation between electrical conductivity and nitrogen content to the calcination temperature results in an interplay between the two descriptors, causing the frequently observed volcano-behavior between hydrochlorination activity and calcination temperature, rationalized here for the first time. Finally, this understanding enabled us to design the first $\mathrm{N}$-doped carbon catalyst that rivals benchmark gold-based systems, bridging the gap between the two catalyst families in acetylene hydrochlorination.

\section{ASSOCIATED CONTENT}

\section{AUTHOR INFORMATION}

\section{Corresponding Author}

*J.P.-R.: tel, +41 44633 7120; email, jpr@chem.ethz.ch.

\section{ORCID}

Ronghe Lin: oooo-0oo2-6798-5321

Selina K. Kaiser: oooo-0oo2-8718-4417

Roland Hauert: oooo-ooo1-6154-9337

Javier Pérez-Ramírez: 0ooo-0002-5805-7355

\section{Author Contributions}

$\S_{\text {}}$ These authors contributed equally.

\section{Funding Sources}

ETH Research Grant (ETH-40 17-1) and Swiss National Science Foundation (project no. 200021-156107).

\section{Notes}

The authors declare no competing financial interest.

\section{Supporting Information.}

The Supporting Information is available free of charge on the ACS Publications website at DOI: .

Experimental details, kinetic studies, and additional reaction and characterization data (PDF)

\section{ACKNOWLEDGMENT}

ScopeM of ETH Zurich is acknowledged for the use of their facilities. The service for Microelemental Analysis at ETH Zurich is acknowledged for $\mathrm{CHN}$ analysis. We are grateful to
Dr. Antonio J. Martín, Dr. René Verel, Mr. Sami Bolat, and Mr. Jan-Georg Rosenboom for their assistance with SEM, NMR, electrical conductivity, and molecular weight measurements, respectively.

\section{REFERENCES}

(1) Zhai, Y. P.; Dou, Y. Q.; Zhao, D. Y.; Fulvio, P. F.; Mayes, R. T.; Dai, S. Adv. Mater. 2011,23, 4828-4850.

(2) To, J. W. F.; He, J. J.; Mei, J. G.; Haghpanah, R.; Chen, Z.; Kurosawa, T.; Chen, S. C.; Bae, W. G.; Pan, L. J.; Tok, J. B. H.; Wilcox, J.; Bao, Z. N. J. Am. Chem. Soc. 2016, 138, 1001-10o9.

(3) He, J. J.; To, J. W. F.; Psarras, P. C.; Yan, H. P.; Atkinson, T.; Holmes, R. T.; Nordlund, D.; Bao, Z. N.; Wilcox, J. Adv. Energy Mater. 2016, 6, 1502491.

(4) Liang, H. W.; Wei, W.; Wu, Z. S.; Feng, X. L.; Müllen, K. J. Am. Chem. Soc. 2013, 135, 16002-16005.

(5) Guo, D. H.; Shibuya, R.; Akiba, C.; Saji, S.; Kondo, T.; Nakamura, J. Science 2016, 351, 361-365.

(6) Li, X.; Pan, X.; Yu, L.; Ren, P.; Wu, X.; Sun, L.; Jiao, F.; Bao, X. Nat. Commun. 2014, 5, 3688.

(7) Dai, B.; Chen, K.; Wang, Y.; Kang, L.; Zhu, M. ACS Catal. 2015, 5, 2541-2547.

(8) Chao, S.; Zou, F.; Wan, F.; Dong, X.; Wang, Y.; Wang, Y.; Guan, Q.; Wang, G.; Li, W. Sci. Rep. 2017, 7, 39789.

(9) Niu, W.; Li, L.; Liu, X.; Wang, N.; Liu, J.; Zhou, W.; Tang, Z.; Chen, S. J. Am. Chem. Soc. 2015, 137, 5555-5562.

(10) Lozano-Castelló, D.; Calo, J. M.; Cazorla-Amorós, D.; Linares-Solano, A. Carbon 2007, 45, 2529-2536.

(11) Geng, H.-Z.; Kim, K. K.; So, K. P.; Lee, Y. S.; Chang, Y.; Lee, Y. H. J. Am. Chem. Soc. 2007, 129, 7758-7759.

(12) Arrigo, R.; Hävecker, M.; Wrabetz, S.; Blume, R.; Lerch, M.; McGregor, J.; Parrott, E. P. J.; Zeitler, J. A.; Gladden, L. F.; KnopGericke, A.; Schlögl, R.; Su, D. S. J. Am. Chem. Soc. 2010, 132, 9616-9630.

(13) Delamar, M.; Hitmi, R.; Pinson, J.; Saveant, J. M. J. Am. Chem. Soc. 1992, 114, 5883-5884.

(14) Su, D. S.; Wen, G. D.; Wu, S. C.; Peng, F.; Schlögl, R. Angew. Chem. Int. Ed. 2017, 56, 936-964.

(15) Liu, X.; Dai, L. Nat. Rev. Mater. 2016, 1, 16064.

(16) Zhao, Z.; Li, M.; Zhang, L.; Dai, L.; Xia, Z. Adv. Mater. 2015, 27, 6834-6840.

(17) Figueiredo, J. L.; Pereira, M. F. R. Catal. Today 2010, 150, 2-7. (18) Trotus, I. T.; Zimmermann, T.; Schüth, F. Chem. Rev. 2014, 114, 1761-1782.

(19) Lin, R.; Amrute, A. P.; Pérez-Ramírez, J. Chem. Rev. 2017, 117, 4182-4247.

(20) United Nations Environment Programme, Minamata Convention on Mercury, www.mercuryconvention.org/ (Accessed Aug 28, 2017).

(21) Malta, G.; Kondrat, S. A.; Freakley, S. J.; Davies, C. J.; Lu, L.; Dawson, S.; Thetford, A.; Gibson, E. K.; Morgan, D. J.; Jones, W.; Wells, P. P.; Johnston, P.; Catlow, C. R. A.; Kiely, C. J.; Hutchings, G. J. Science 2017, 355, 1399-1403.

(22) Conte, M.; Davies, C. J.; Morgan, D. J.; Davies, T. E.; Elias, D. J.; Carley, A. F.; Johnston, P.; Hutchings, G. J. J. Catal. 2013, 297, 128-136.

(23) Hutchings, G. J. J. Catal. 1985, 96, 292-295.

(24) Nkosi, B.; Coville, N. J.; Hutchings, G. J. Appl. Catal. 1988, 43, 33-39.

(25) Oliver-Meseguer, J.; Doménech-Carbó, A.; Boronat, M.; Leyva-Pérez, A.; Corma, A. Angew. Chem. Int. Ed. 2017, 56, 64356439 .

(26) Johnston, P.; Carthey, N.; Hutchings, G. J. J. Am. Chem. Soc. 2015, 137, 14548-14557.

(27) Zhu, M.; Wang, Q.; Chen, K.; Wang, Y.; Huang, C.; Dai, H.; Yu, F.; Kang, L.; Dai, B. ACS Catal. 2015, 5, 5306-5316. 
(28) Li, X. Y.; Wang, Y.; Kang, L. H.; Zhu, M. Y.; Dai, B. J. Catal. 2014, 311, 288-294.

(29) Zhang, C. L.; Kang, L. H.; Zhu, M. Y.; Dai, B. RSC Adv. 2015, 5, 7461-7468.

(30) Zhou, K.; Li, B.; Zhang, Q.; Huang, J. Q.; Tian, G. L.; Jia, J. C.; Zhao, M. Q.; Luo, G. H.; Su, D. S.; Wei, F. ChemSusChem 2014,-7, 723-728.

(31) Wang, X. G.; Dai, B.; Wang, Y.; Yu, F. ChemCatChem 2014, 6, 2339-2344.

(32) Li, X.; Li, P.; Pan, X.; Ma, H.; Bao, X. Appl. Catal., B. 2017, 210, 116-120.

(33) Qiao, M.; Tang, C.; He, G.; Qiu, K.; Binions, R.; Parkin, I. P.; Zhang, Q.; Guo, Z.; Titirici, M. M. J. Mater. Chem. A 2016, 4, 12658-12666.

(34) Yang, D. S.; Chaudhari, S.; Rajesh, K. P.; Yu, J. S. ChemCatChem 2014, 6, 1236-1244.

(35) Gospodinova, N.; Terlemezyan, L. Prog. Polym. Sci. 1998, 23, 1443-1484.

(36) Sapurina, I. Y.; Shishow, M. A. In New Polymers for Special Applications, $1^{\text {st }}$ ed.; Gomes, A. S., Eds.; InTech Open Access Publisher: Rijeka, 2012; p 252.

(37) Trchová, M.; Stejskal, J. Pure Appl. Chem. 2o11, 83, 1803-1817.

(38) Stejskal, J.; Trchová, M. Polym. Int. 2012, 61, 240-251.

(39) Wehrle, B.; Mortensen, J.; Limbach, H.-H.; Heinze, J. Adv. Mater. 1989, 1, 441-443.

(40) Křriž, J.; Konyushenko, E. N.; Trchová, M.; Stejskal, J. Polym. Int. 2011, 6o, 1296-1302.

(41) Tan, K. L.; Tan, B. T. G. Phys. Rev. B 1989, 39, 8070-8073.

(42) Golczak, S.; Kanciurzewska, A.; Fahlman, M.; Langer, K.; Langer, J. Solid State Ionics 2oo8, 179, 2234-2239.

(43) To, J. W. F.; Chen, Z.; Yao, H.; He, J.; Kim, K.; Chou, H.-H.; Pan, L.; Wilcox, J.; Cui, Y.; Bao, Z. ACS Cent. Sci. 2015, 1, 68-76.

(44) Ding, W.; Wei, Z. D.; Chen, S. G.; Qi, X. Q.; Yang, T.; Hu, J. S.; Wang, D.; Wan, L. J.; Alvi, S. F.; Li, L. Angew. Chem. Int. Ed. 2013, 52, 11755-11759.

(45) Wang, X.; Hou, Z.; Ikeda, T.; Terakura, K. J. Phy. Chem. C 2014, 118, 13929-13935.

(46) Duan, X.; Tian, X.; Ke, J.; Yin, Y.; Zheng, J.; Chen, J.; Cao, Z.; Xie, Z.; Yuan, Y. Chem. Sci. 2o16, 7, 3181-3187.

(47) Zhou, K.; Jia, J.; Li, C.; Xu, H.; Zhou, J.; Luo, G.; Wei, F. Green Chem. 2015, 17, 356-364.

(48) Li, B.; Sun, X. Y.; Su, D. S. Phys. Chem. Chem. Phys. 2015, 17, 6691-6694. 


\section{Table of Contents}

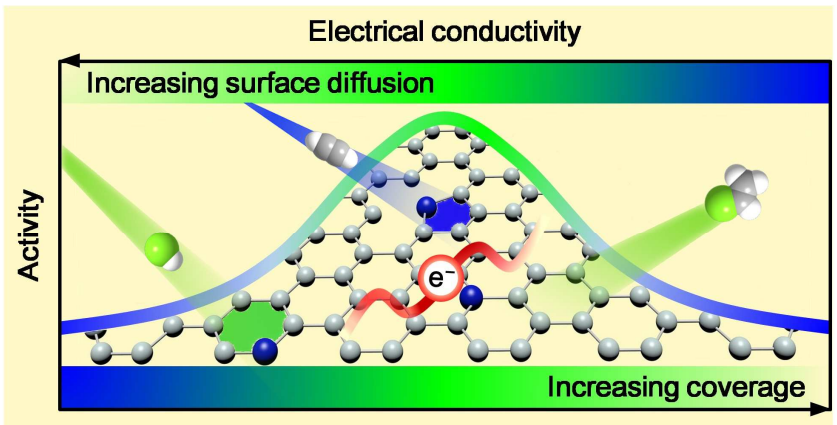

Pyrrolic and pyridinic nitrogen contents

15

16

17

18 